\title{
Recent Strategies for the Management of Renal Angiomyolipoma: A Review of Diagnostic and Therapeutic Approaches
}

\author{
Alireza Akhavan Rezayat, ${ }^{1}$ Mohammad Aslezare, ${ }^{1}$ Hassan Ahmadnia, ${ }^{1}$ Salman Soltani, ${ }^{1}$ and Amirabbas \\ Asadpour ${ }^{1, *}$ \\ ${ }^{1}$ Department of Urology, School of Medicine, Mashhad University of Medical Sciences, Mashhad, Iran \\ "Corresponding author: Amirabbas Asadpour, Ghaem Hospital, Mashhad, Iran. Tel: +98-9153148223, Fax: +98-5138012857, E-mail: asadpoura@mums.ac.ir
}

Received 2017 May 29; Revised 2017 July 14; Accepted 2017 September 18.

\begin{abstract}
Recent prophylactic treatment options and diagnostic tools show a suboptimal improvement in patients with renal angiomyolipoma (AML). This study was an attempt to review management strategies applied before invasive options. An extensive research on medical databases such as PubMed and Scopus was performed from 1999 to 2016 using the following keywords: 'kidney', 'renal', and 'angiomyolipoma'. All related studies on patients treating with conservative or minimally-invasive procedures were included. However, reports on surgical treatments were excluded. Treatment strategies have been selected based on outcomes resulting from computed tomography (CT) and magnetic resonance (MR) imaging. Fat content and tumor size are the most common used indications for AMLs. Unenhanced CT and chemical shift imaging provide good evidence in case of fat-poor AMLs. Chemical analysis and percutaneous biopsy are recommended in case of a diagnostic challenge. A tumor size of $6 \mathrm{~cm}$ or larger in diameter might necessitate invasive treatment, while AMLs patients with tumors around $4 \mathrm{~cm}$ may require prophylactic treatment. Of all treatment options, embolization indicated a high risk of reintervention. Moreover, everolimus and sirolimus as 2 inhibitors of mammalian target of rapamycin (mTOR) have been evaluated in clinical trials and demonstrated promising outcomes. In conclusion, advances in imaging techniques along with mTOR inhibitors and embolic materials potentiate functional outcomes in AMLs.
\end{abstract}

Keywords: Angiomyolipoma, Kidney, Imaging, Fat, Embolization, Reintervention

\section{Introduction}

Renal angiomyolipoma (AML) is described as a benign mesenchymal neoplasm containing different proportions of triphasic histology, abnormal thick-walled blood vessels, spindle and epithelioid smooth muscle cells, and adipose tissue (1). Nevertheless, AMLs are more likely to enlarge upon the renal venous system and present vascular invasion and lymph node engagement (1). It has been widely confirmed that AML belongs to the perivascular epithelioid cell tumor family (2). Two well-known types have been distinguished including sporadic isolated AML and AML associated with tuberous sclerosis (3). On the other hand, epithelioid AML (EAML) is a potentially malignant mesenchymal neoplasm, which may involve lymph node metastasis and distant metastasis (4). Typically, renal AMLs are variable mixture of 3 mesenchymal constituents: (1) smooth muscle cells, (2) adipose tissue, and (3) blood vessels. This disease, especially tuberous sclerosis complex (TSC)-associated AMLs, causes substantially higher health care utilization and costs (5). Therefore, an update is required on available options for patients and clinicians to make a solid decision. In this review, we attempted to provide the more recent applicable methods for diagnosis and treatment of renal AMLs.

\section{Methods}

Major electronic databases containing Web of Science, PubMed, SID, Google Scholar, and Scopus were searched during 1999 and 2016 for diagnostic tools and therapeutic options on renal AMLs. The key terms for this study were as follow: 'kidney', 'renal', and 'angiomyolipoma'. All case series with a minimum of 7 patients, case reports during pregnancy, and human trials on drug therapies were reviewed for more detail. Inclusion criteria included those studies concerning diagnosis of AMLs using clinical manifestation, staging criteria, imaging techniques, and histopathological analyses as well as treatment of AMLs applying surveillance, embolization, ablation, and inhibitor drugs. Studies involved any invasive procedures such as partial nephrectomy were excluded.

\subsection{Diagnosis}

\subsubsection{Clinical Presentations}

Despite the existing guideline recommendations regarding AML, its incidental diagnosis based on hemor- 
rhagic presentation (Wunderlich syndrome) is on the rise due to liberal abdominal imaging (6). Most isolated AMLs are found through an incidental imaging, while multiple AMLs are largely detected by the diagnostic workup in patients with suspected TSC (7). The main indications for the management of AMLs include the presentation of symptoms or suspected malignancy (8). The common symptoms of AML include the presence of abdominal pain, palpable mass, and hematuria associated with renal masses. The first is more frequent in AMLs, whereas hematuria is associated with TSC in these patients. However, recent reports on the frequencies of such symptoms have been indicative of a general reduction in these clinical manifestations; for instance, the rate of pain was $37 \%$ to $41 \%$, which declined to $35 \%$ over a decade in the 2010 s $(9,10)$. The characteristic feature of renal AML is thick-walled blood vessels, which do not have normal elastin and are prone to rupture (11). Aneurysm size (close to $5 \mathrm{~mm}$ ) and tumor size (close to $4 \mathrm{~cm}$ ) significantly account for rupture and hemorrhage (12). Likewise, another study revealed that tumors with serial changes in volumes were associated with higher probability of hemorrhagic lesions (13). As for TSC patients, their tumors tend to be multifocal, bilateral, and larger when compared to those tumors in sporadic AMLs (10). AML in pregnant women often remains undetectable with the equivocal risk of rupture (14).

\subsubsection{Staging Criteria}

Age, number of embolization procedures, and embolization rate were reported as a correlate of AML stage. Moreover, patients with renal AML at higher stages mainly presented with adverse kidney complications. Therefore, AML staging criteria can be used reliably as a valuable diagnostic tool to assess disease burden during initial workup and a scale to clinicians for keeping a track of AML progression. However, there is a lack of valid staging criteria for wide applications in clinical practice. Although anemia is a surrogate marker, some other clinical features, which are related to kidney disorders including hypertension, poor kidney function, and blood transfusion only appear at higher stage of AML (15).

\subsubsection{Imaging}

Along with the growing use of diagnostic imaging tests by ultrasound and CT, more renal AMLs can be detected at random (16). Another characteristic feature of AMLs is abundant fat tissue (17), easily detected by CT or MR images (18). Fat-containing renal cell carcinomas (RCC) are the distinctive feature of fat-containing renal tumors even though intratumoral fat also occurs mostly in case of AML (19). Ultrasound findings usually show hyperechoic lesions; in this manner, spectral fat suppression im- ages using MR is suggestive of macroscopic fat in AML (20). Minimal fat AMLs contain only microscopic fat, thus, it is difficult to differentiate them from renal neoplasms (21). Despite the diagnostic potential of ultrasound, its overall reliability is not extensively confirmed as a confident tool to distinguish AMLs. This does not mean, however, that ultrasound images cannot be utilized to follow AML progression (22). Conversely, CT with high sensitivity, specificity, negative (NPV), and positive predictive (PPV) values exhibits fat density in the range of -10 and $-100 \mathrm{HU}$ (Hounsfield units).

On unenhanced CT scans, AML with minimal fat reveals a lesion without fat attenuation (23). Using unenhanced CT or MR images can categorize AMLs based on the amount of fat (18). Unenhanced CT shows AMLs with rich content of fat as lesions below -10 HU. Chemical shift imaging (CSI) can detect fat-poor AMLs when tumor-to-spleen ratio (TSR) is lower than 0.71, or signal intensity index (SII) is higher than $16.5 \%$. Fat-invisible cases are characterized as TSR $\geq$ 0.71 and $\mathrm{STT} \leq 16.5 \%$. Differentiating AMLs without rich content of fat form RCC is a dilemma as TSR or SII of theses subtypes of AML overlaps with that of RCC due to intracytoplasmic lipid (24). As an alternative, when AML is hyperattenuating on unenhanced CT or homogeneously enhancing on contrast-enhanced CT, MR imaging provides conclusive evidence to differentiate AML from RCC. AMLs with hypointense and homogeneously enhancing lesions on MRI need percutaneous biopsy (25). Therefore, fat-rich AML or classic AML is easily diagnosed by unenhanced CT scans. Fat-poor AML (i.e., isoattenuating AML) is measured between -10 HU and $45 \mathrm{HU}$, indicating signal loss on opposedphase images, yet being without signal drop on CSI. Fatinvisible AML (i.e., hyperattenuating AML, AML with epithelial cyst, and epithelioid AML) is gauged above $45 \mathrm{HU}$ or fails to show a considerable signal drop on CSI (18).

\subsubsection{Histopathology}

The chief cell type of renal AML may be the spindle cells closely corresponded to the vascular walls. Calponin immunoreactivity has been shown in these cells. Furthermore, the cells were either positive staining of the muscle markers calponin or muscle-specific actin. Another cell population in renal AML is epithelioid cells that may be found as the most predominant type in some cases. The cell of origin and melanoma-associated antigen immunoreactivity of the epithelioid cells still pose controversy (26). However, its clonal nature has been reported (27). This cell type exhibits an epithelioid appearance, a clear to granular cytoplasm, a round to oval, centrally located nucleus, an inconspicuous nucleolus, and a typical perivascular location (28). Ultrastructural results revealed microfilament bundles with electron-dense 
condensation, numerous mitochondria, and membranebound dense granules in perivascular epithelioid cell (29). The adipocytic cells, as the third cell population of AML, have stained positive for both the melanosome and melanoma markers and the smooth muscle markers, while stained negative for S100, indicating fatty metamorphosis. Ultrastructural examinations of adipocytic cells have demonstrated fat as an abundant component of the cytoplasmic volume that spreads apart from cytoplasmic organelles across a larger cell volume. This was corroborated with the positive immunostaining of adipocytic cells for both melanocytic and smooth muscle markers. Therefore, renal AML is a tumor consisting of smooth muscle cells and secondary morphoimmunophenotypic differentiation (2).

In immunohistochemical analysis, AML is diagnosed by the expression of both melanocytic markers (HMB-45 and Mart-1/ Melan A) and myoid markers (smooth muscle actin and muscle-specific actin) (2). When applying transmission electron microscopy, premelanosome-like crystalloid structures were evident in the cytoplasm of the smooth muscle cells of renal AML (30). Besides, cytoplasmic periodic acid-Schiff-positive diastase-resistant rhomboid crystals, with no renin immunoreactivity, have been found in renal AML (31). Although the definitive criteria for EAML have not been specified, several large-scale studies have described EAML as follow: large tumor size $(>7$ $\mathrm{cm})$, severe cytologic or nuclear atypia, extent of nuclear atypia ( $\geq 70 \%$ atypical epithelioid cells), (extensive) tumor necrosis, large epithelioid cell component, mitotic count ( $\geq 2$ mitosis per 10 high power fields (HPFs)), atypical mitotic figures, lymphovascular invasion, associated TSC or concurrent AML, extrarenal extension and/or renal vein involvement, and carcinoma-like growth patterns (4, 26 ). The presence of 3 or more of these features put the patient at a high risk of clinically malignant EAML. Moreover, recent clinicopathologic studies on a large series of AML patients suggested the proportion of epithelioid component $(>10 \%)$ and the degree of atypia in epithelioid cells as strong factors for the diagnosis of EAML. The malignant EAML was associated with a tumor size $>7 \mathrm{~cm}$, a higher percentage epithelioid component, $\geq 70 \%$ atypical epithelioid cells, $\geq 2$ mitosis per 10 HPFs, atypical mitotic figures, necrosis, extrarenal extension, lymphovascular invasion, and carcinoma-like growth pattern. Additionally, the malignant EAML might demonstrate p53 immunoreactivity (32). Some studies reported p53 mutations or diffuse p53 positivity in the malignant epithelioid cells (33). Accordingly, decreased membranous E-cadherin expression and strong p53 positivity might be indicative of malignant transformation of EAML (34).

\subsection{Treatment}

Considering the state-of-the-art diagnostic tools, the management of renal AML is still based on old and biased studies (6). According to European association of urology guidelines, eligibility criteria for treatment include large tumors, presence of symptoms, those in women of childbearing age, and where there is inadequate follow-up control or health care access issues (35). A tumor size for treatment is still enigma although some have reported a threshold around 3 to $4 \mathrm{~cm}$. moreover, because most of AMLs are detected incidentally $(9,10,14)$, decision-making for treatment is complicated, when a patient presents with a large ( $>4 \mathrm{~cm}$ ) and asymptomatic AML (14). The main aims of different treatment methods are prevention of acute events and protection of renal parenchyma in addition to the preservation of long-term kidney function. Prophylactic treatment methods at the time of this study were observation, ablation, mTOR inhibitor, and embolization. These procedures, however, cause less complications and adverse effects compared with surgery (8). Therefore, in this study, more attention is paid to prophylactic treatment.

Currently, the guidelines for renal AMLs indicate a 1to-3 year monitoring rate during the patient's lifetime; nonetheless, the age when active surveillance and monitoring should start is not exactly specified (36). Some studies define a range of 8.6 to 11.3 years as the median age of initial AML detection (37). Therefore, beginning to monitor the patients when $\mathrm{h} / \mathrm{she}$ is approaching the age of 10 years would result in the early detection of AMLs; in other words, active surveillance of patients, which initiates no later than the age of 10 years and maintains during their life while increasing the number of monitoring with advancing age, is highly suggested for AMLs patients associated with TSC (36). All studies put emphasis on early detection and treatment to prevent progressive damage to renal tissue and enhance patient outcomes (38). A tumor size of no more than $4 \mathrm{~cm}$ was suggested for the observation of asymptomatic AMLs (9). Accordingly, AMLs are frequently examined intensively using imaging tools and treated empirically as the 4-cm size limit is met (14). A recent study reported that AMLs less than $6 \mathrm{~cm}$ in diameter should undergo conservative treatment (8).

Routinely, embolization has been employed for symptomatic cases with bleeding (9). Moreover, elective embolization is also reserved for patients with large growing AML to stop hemorrhage and preserve kidney function (39, 40). More recently, this procedure was used for asymptomatic (nonhemorrhagic) large AMLs with serial growth as well. Embolization occludes aneurysmal blood vessels, decreases AML size, and potentiates additional growth owing to its impact on afferent vessels, which, in turn, con- 
tributes to preservation of kidney function. Selective angioembolization is successfully used prophylactically in patients representing bleeding $(39,41)$. The current studies recommend an optimal threshold of $>10 \mathrm{~cm}$ for embolization, which is more different than the prior reports that specified a limit around $4 \mathrm{~cm}(39,41)$. Nevertheless, there have been some reports on the failure of embolization in restricting the blood supply to the lesion. On a pooled analysis, embolization was indicated to be associated with a considerably high risk of reintervention even if the mean tumor diameter was lower than $8 \mathrm{~cm}$. When tumor is large with high vascularity, embolization showed less efficacious outcomes than partial nephrectomy (8). Irrespective of the embolization type (elective or nonelective), patients who receive this treatment experience significant anemia, hypertension, and reduced kidney function (38). The most serious complications, which are often reported in patients undergoing embolization, include pain and increased temperature, known as postembolization syndrome. More to the point, the failure rate diminishes by repeating the procedure. Embolization poses a formidable challenge if AMLs are multifocal or there is a severe atheromatosis in the aorta (42). Sooriakumaran et al. observed some procedure-related complications including postembolization syndrome, abscess formation, nonfunctioning kidney, and refractory hypertension derived from segmental renal infarct (10). Distinct embolic materials have been applied for AMLs such as polyvinyl alcohol, particles, gelfoam, alcohol or N-butyl cyanoacrylate, liquid ethylene vinyl alcohol copolymer, and coils (40). In this procedure, to decrease the risk of AML regrowth by new collateralization, it is recommended to embolize both the distal tumoral capillary bed and the proximal feeding vessels. Some studies have reported a recurrence rate of $10 \%$ to $42.9 \%$ (39-41). The statistics significantly increase in AML patients associated with TSC (41). Radiofrequency ablation is another promising treatment, which is already reserved for smaller lesions, yet a suitable option in AMLs $>6 \mathrm{~cm}$, particularly if associated with saline-cooled electrodes (8). No recurrence has been observed for this technique, especially in case of small tumors (8). There have been 3 large case series, where ablation therapies were used for the treatment of a subtype of AMLs including 15 patients with intraoperative biopsy confirmed renal AML, 280 cases with small renal masses, and 7 with pathologically confirmed renal AML; the results revealed that ablative techniques are safe, efficient, and minimally invasive for the treatment of AMLs (43). However, using cryoablation for large AMLs is associated with some retroperitoneal bleeding, which may occur during the treatment (8). Moreover, it may be associated with some postoperative complications such as those related to the procedure, that is, transient hematuria and intercostals nerve transection, or those related to the surgery (i.e., myocardial infarction and pneumonia) (43). As for borderline surgical candidates, it has been shown that each considerable change in the postcontrast-enhanced imaging probability of a benign or indolent lesion allows surgery to be suspended and is more likely to impact the pursuit of biopsy, active surveillance, or percutaneous ablative therapy (44).

When it comes to pregnant women, the guidelines necessitate the treatment of AMLs. There is no conclusive option for AML in pregnancy. The existing evidence comes for case reports (45). As AMLs, either the TSC or sporadic lymphangioleiomyomatosis, demonstrate mutations in tuberous sclerosis genes, mTOR is activated, and thus, the suppression of this signaling can be regarded as a preemptive treatment (46). Sirolimus known as rapamycin has trialed in TSC patients and come up with tumor regression. This outcome is obtained when the patients remain on treatment; in other words, an increase in tumor volume occurred as the drug administration was cut off (47). This was also reported by another multicenter Phase 2 trial (48). Moreover, some serious adverse effects were documented: diarrhea, pyelonephritis, stomatitis, and respiratory infections (47). Grade 1 or 2 adverse events including mouth ulcers, hyperlipidemia, and peripheral edema were observed in 13 patients treated with sirolimus for up to 1 year (49). Nevertheless, the safety and efficacy of sirolimus were proved in long-term trials (49). In a multicenter, randomized, double-blind, placebocontrolled trial, everolimus, another rapamycin derivative, caused a higher response rate as compared to placebo ( $42 \%$ vs. $0 \%$ ) and reduced tumor volume in $80 \%$ of patients with TSC or sporadic lymphangioleiomyomatosis AML on Week 24. The striking adverse effects in this case involve stomatitis, nasopharyngitis, and acne-like skin lesions (50). In another trial on TSC AML in patients with subependymal giant cell astrocytoma (SEGA), everolimus caused a decline of more than $50 \%$ in the tumor volume (51). Both these studies confirmed the efficiency and safety of everolimus $(50,51)$. All in all, according to the international TSC consensus group, recent recommendations for the treatment of AML patients with TSC, particularly in case of acute hemorrhage, include embolization and corticosteroids; as for asymptomatic lesions with a size larger than $3 \mathrm{~cm}$, the administration of mTOR inhibitors followed by selective arterial emobilization or partial resection is recommended (36). The use of mTOR inhibitors was also reserved for metastatic epithelioid AML (14). 


\section{Conclusions}

AMLs are mesenchymal tumors, most of which occurring in the kidney. They are mostly diagnosed on random based on axial imaging or due to the presentation of hemorrhage. The presence of fat on unenhanced CT or CSI is suggestive of AML as well. Furthermore, the characteristic features of AMLs are the positive expression of HMB-45, Melan-A, and SMA, while negative for S-100 and cytokeratin. Complicated medical conditions such as severe bleeding events associated with AML are of utmost importance for the choice of the prophylactic treatment strategy. Two paramount factors often determine the likelihood of bleeding, vascularity, and size of the tumor. As for tumor size, a threshold of $6 \mathrm{~cm}$ in diameter is utilized for many criteria of invasive intervention. Conservative methods would be appropriate for AMLs less than $4 \mathrm{~cm}$. Prognosis estimation for malignant AMLs can be examined by immunohistochemical analysis. When it comes to the treatment of AML, active surveillance is still considered as the most reasonable first-line option for many patients with AMLs, particularly asymptomatic subjects (i.e., sporadic AMLs), with small tumors. Embolization is the preeminent prophylactic treatment strategy in patients with symptomatic AMLs or large tumors. However, there is a high risk of reintervention, which has indicated suboptimal outcomes following embolization. In managing AML patients with TSC, mTOR inhibitors showed promising outcomes in some clinical trials. In pregnant patients, conservative options along with embolization are preferred to reduce the risk of spontaneous rupture.

\section{References}

1. Martignoni G, Cheville J, Fletcher CDM. In: World health organization classification of tumours of the urinary system and male genital organs. Moch A, Humphrey PA, Ulbright TM, Reuter V, editors. Lyon: IARC Press; 2016. pp. 62-5.Angiomyolipoma.

2. Stone $\mathrm{CH}$, Lee MW, Amin MB, Yaziji $\mathrm{H}$, Gown AM, Ro JY, et al. Renal angiomyolipoma: further immunophenotypic characterization of an expanding morphologic spectrum. Arch Pathol Lab Med. 2001;125(6):751-8. doi: 10.1043/00039985(2001)125<0751:RA>2.0.CO;2. [PubMed: 11371226].

3. Al Omran B, Ansari N. Aneurysm in a Large Sporadic Renal Angiomyolipoma. Oman Med J. 2016;31(3):223-6. doi: 10.5001/omj.2016.42. [PubMed: 27162594].

4. Lei JH, Liu LR, Wei Q, Song TR, Yang L, Yuan HC, et al. A Four-Year Follow-up Study of Renal Epithelioid Angiomyolipoma: A MultiCenter Experience and Literature Review. Sci Rep. 2015;5:10030. doi: 10.1038/srep10030. [PubMed: 25939249].

5. Song X, Liu Z, Cappell K, Gregory C, Said Q, Prestifilippo J, et al. Healthcare utilization and costs in patients with tuberous sclerosiscomplexrelated renal angiomyolipoma. J Med Econ. 2017;20(4):388-94. doi: 10.1080/13696998.2016.1272461.

6. Laguna MP. Re: Natural History of Renal Angiomyolipoma (AML): Most Patients with Large AMLs $>4 \mathrm{~cm}$ can be Offered Active Surveillance as an Initial Management Strategy. J Urol. 2016;196(5):1397-8. doi:10.1016/j.juro.2016.08.045. [PubMed: 27751445].
7. Rakowski SK, Winterkorn EB, Paul E, Steele DJ, Halpern EF, Thiele EA. Renal manifestations of tuberous sclerosis complex: Incidence, prognosis, and predictive factors. Kidney Int. 2006;70(10):1777-82. doi: 10.1038/sj.ki.5001853. [PubMed: 17003820].

8. Kuusk T, Biancari F, Lane B, Tobert C, Campbell S, Rimon U, et al. Treatment of renal angiomyolipoma: pooled analysis of individual patient data. BMC Urol. 2015;15:123. doi: 10.1186/s12894-015-0118-2. [PubMed: 26710923].

9. Nelson CP, Sanda MG. Contemporary diagnosis and management of renal angiomyolipoma. J Urol. 2002;168(4 Pt 1):1315-25. doi: 10.1097/01.ju.0000028200.86216.b2. [PubMed: 12352384].

10. Sooriakumaran P, Gibbs P, Coughlin G, Attard V, Elmslie F, Kingswood $\mathrm{C}$, et al. Angiomyolipomata: challenges, solutions, and future prospects based on over 100 cases treated. BJU Int. 2010;105(1):101-6. doi: 10.1111/j.1464-410X.2009.08649.x. [PubMed: 19493268].

11. Eble JN. Angiomyolipoma of kidney. Semin Diagn Pathol. 1998;15(1):2140. [PubMed: 9503504]

12. Yamakado K, Tanaka N, Nakagawa T, Kobayashi S, Yanagawa M, Takeda K. Renal angiomyolipoma: relationships between tumor size, aneurysm formation, and rupture. Radiology. 2002;225(1):78-82. doi: 10.1148/radiol.2251011477. [PubMed: 12354988].

13. Kingswood JC, Doyle T, Cox J. The natural history of renal angiomyolipoma (AMLS) in tuberous sclerosis complex (TSC). 49th ERA-EDTA Congress. Paris, France. .

14. Bhatt JR, Richard PO, Kim NS, Finelli A, Manickavachagam K, Legere L, et al. Natural History of Renal Angiomyolipoma (AML): Most Patients with Large AMLs $>4 \mathrm{~cm}$ Can Be Offered Active Surveillance as an Initial Management Strategy. Eur Urol. 2016;70(1):85-90. doi: 10.1016/j.eururo.2016.01.048. [PubMed: 26873836].

15. Nasri H. Renal Cell Protection of Erythropoietin beyond Correcting The Anemia in Chronic Kidney Disease Patients. Cell J. 2014;15(4):37880. [PubMed: 24381864].

16. Smith SJ, Bosniak MA, Megibow AJ, Hulnick DH, Horii SC, Raghavendra BN. Renal cell carcinoma: earlier discovery and increased detection. Radiology. 1989;170(3 Pt 1):699-703. doi: 10.1148/radiology.170.3.2644658. [PubMed: 2644658].

17. Halpenny D, Snow A, McNeill G, Torreggiani WC. The radiological diagnosis and treatment of renal angiomyolipoma-current status. Clin Radiol. 2010;65(2):99-108. doi: 10.1016/j.crad.2009.09.014. [PubMed: 20103431].

18. Song S, Park BK, Park JJ. New radiologic classification of renal angiomyolipomas. Eur J Radiol. 2016;85(10):1835-42. doi: 10.1016/j.ejrad.2016.08.012. [PubMed: 27666625].

19. Simpson E, Patel U. Diagnosis of angiomyolipoma using computed tomography-region of interest $<$ or $=-10 \mathrm{HU}$ or 4 adjacent pixels $<$ or $=-10 \mathrm{HU}$ are recommended as the diagnostic thresholds. Clin Radiol. 2006;61(5):410-6. doi: 10.1016/j.crad.2005.12.013. [PubMed: 16679114].

20. Nikken JJ, Krestin GP. MRI of the kidney-state of the art. Eur Radiol. 2007;17(11):2780-93. doi: 10.1007/s00330-007-0701-3. [PubMed: 17646992].

21. Kim JK, Kim SH, Jang YJ, Ahn H, Kim CS, Park H, et al. Renal angiomyolipoma with minimal fat: differentiation from other neoplasms at double-echo chemical shift FLASH MR imaging. Radiology. 2006;239(1):174-80. doi: 10.1148/radiol.2391050102. [PubMed: 16507752].

22. Steiner MS, Goldman SM, Fishman EK, Marshall FF. The natural history of renal angiomyolipoma. J Urol. 1993;150(6):1782-6. doi: 10.1016/S0022-5347(17)35895-0. [PubMed: 8230504].

23. Jinzaki M, Silverman SG, Tanimoto A, Shinmoto H, Kuribayashi S. Angiomyolipomas that do not contain fat attenuation at unenhanced CT. Radiology. 2005;234(1):311. doi: 10.1148/radiol.2341041128. [PubMed: 15618388] author reply 311-2.

24. Jeong CJ, Park BK, Park JJ, Kim CK. Unenhanced CT and MRI Parameters That Can Be Used to Reliably Predict Fat-Invisible Angiomyolipoma. 
AJR Am J Roentgenol. 2016;206(2):340-7. doi: 10.2214/AJR.15.15086. [PubMed: 26797361].

25. Silverman SG, Israel GM, Herts BR, Richie JP. Management of the incidental renal mass. Radiology. 2008;249(1):16-31. doi: 10.1148/radiol.2491070783. [PubMed: 18796665].

26. Brimo F, Robinson B, Guo C, Zhou M, Latour M, Epstein JI. Renal epithelioid angiomyolipoma with atypia: a series of 40 cases with emphasis on clinicopathologic prognostic indicators of malignancy. Am J Surg Pathol. 2010;34(5):715-22. doi: 10.1097/PAS.ob013e3181d90370. [PubMed: 20410812].

27. Cheng L, Gu J, Eble JN, Bostwick DG, Younger C, MacLennan GT, et al. Molecular genetic evidence for different clonal origin of components of human renal angiomyolipomas. Am J Surg Pathol. 2001;25(10):12316. doi: 10.1097/00000478-200110000-00002. [PubMed: 11688456].

28. Tazelaar HD, Batts KP, Srigley JR. Primary extrapulmonary sugar tumor (PEST): a report of four cases. Mod Pathol. 2001;14(6):615-22. doi: 10.1038/modpathol.3880360. [PubMed: 11406665].

29. Martignoni G, Pea M, Reghellin D, Zamboni G, Bonetti F. PEComas: the past, the present and the future. Virchows Arch. 2008;452(2):119-32. doi:10.1007/s00428-007-0509-1. [PubMed: 18080139].

30. Kaiserling E, Krober S, Xiao JC, Schaumburg-Lever G. Angiomyolipoma of the kidney. Immunoreactivity with HMB-45. Light- and electron-microscopic findings. Histopathology. 1994;25(1):41-8. doi: 10.1111/j.1365-2559.1994.tb00596.x. [PubMed: 7959644].

31. Mukai M, Torikata C, Iri H, Tamai S, Sugiura H, Tanaka Y, et al. Crystalloids in angiomyolipoma. 1. A previously unnoticed phenomenon of renal angiomyolipoma occurring at a high frequency. Am J Surg Pathol. 1992;16(1):1-10. doi: 10.1097/00000478-19920100000001. [PubMed: 1370190].

32. Sato K, Ueda Y, Tachibana H, Miyazawa K, Chikazawa I, Kaji S, et al. Malignant epithelioid angiomyolipoma of the kidney in a patient with tuberous sclerosis: an autopsy case report with p53 gene mutation analysis. Pathol Res Pract. 2008;204(10):771-7. doi: 10.1016/j.prp.2008.04.008. [PubMed: 18547741].

33. Li J, Zhu M, Wang YL. Malignant epithelioid angiomyolipoma of the kidney with pulmonary metastases and p53 gene mutation. World J Surg Oncol. 2012;10:213. doi: 10.1186/1477-7819-10-213. [PubMed: 23043633].

34. Park JH, Lee C, Suh JH, Kim G, Song B, Moon KC. Renal epithelioid angiomyolipoma: Histopathologic review, immunohistochemical evaluation and prognostic significance. Pathol Int. 2016;66(10):571-7. doi: 10.1111/pin.12458. [PubMed: 27595761].

35. Ljungberg B, Bensalah K, Canfield S, Dabestani S, Hofmann F, Hora $\mathrm{M}$, et al. EAU guidelines on renal cell carcinoma: 2014 update. Eur Urol. 2015;67(5):913-24. doi: 10.1016/j.eururo.2015.01.005. [PubMed: 25616710].

36. Krueger DA, Northrup H, International Tuberous Sclerosis Complex Consensus G. Tuberous sclerosis complex surveillance and management: recommendations of the 2012 International Tuberous Sclerosis Complex Consensus Conference. Pediatr Neurol. 2013;49(4):255-65. doi: 10.1016/j.pediatrneurol.2013.08.002. [PubMed: 24053983].

37. Curatolo P, Bombardieri R. Tuberous sclerosis. Handb Clin Neurol. 2008;87:129-51. doi: 10.1016/S0072-9752(07)87009-6. [PubMed: 18809023].

38. Eijkemans MJ, van der Wal W, Reijnders LJ, Roes KC, van Waalwijk van Doorn-Khosrovani SB, Pelletier C, et al. Long-term Follow-up Assessing Renal Angiomyolipoma Treatment Patterns, Morbidity, and Mortality: An Observational Study in Tuberous Sclerosis Complex Pa- tients in the Netherlands. Am J Kidney Dis. 2015;66(4):638-45. doi 10.1053/j.ajkd.2015.05.016. [PubMed: 26165440].

39. Ramon J, Rimon U, Garniek A, Golan G, Bensaid P, Kitrey ND et al. Renal angiomyolipoma: long-term results following selective arterial embolization. Eur Urol. 2009;55(5):1155-61. doi: 10.1016/j.eururo.2008.04.025. [PubMed: 18440125].

40. Murray TE, Doyle F, Lee M. Transarterial Embolization of Angiomyolipoma: A Systematic Review. J Urol. 2015;194(3):635-9. doi: 10.1016/j.juro.2015.04.081. [PubMed: 25916674].

41. Kothary N, Soulen MC, Clark TW, Wein AJ, Shlansky-Goldberg RD, Crino PB, et al. Renal angiomyolipoma: long-term results after arterial embolization. J Vasc Interv Radiol. 2005;16(1):45-50. doi: 10.1097/01.RVI.0000143769.79774.70. [PubMed: 15640409].

42. Matuszewski M, Michajlowski J, Bianek-Bodzak A, Krajka K. Radiofrequency ablation of small symptomatic angiomyolipomas of the kidney: Report of two cases. Pol J Radiol. 2010;75(3):68-71. [PubMed: 22802796].

43. Castle SM, Gorbatiy V, Ekwenna O, Young E, Leveillee RJ. Radiofrequency ablation (RFA) therapy for renal angiomyolipoma (AML): an alternative to angio-embolization and nephron-sparing surgery. BJU Int. 2012;109(3):384-7. doi: 10.1111/j.1464-410X.2011.10376.x. [PubMed: 22176671].

44. Kang SK, Huang WC, Pandharipande PV, Chandarana H. Solid renal masses: what the numbers tell us. AJR Am J Roentgenol. 2014;202(6):1196-206. doi: 10.2214/AJR.14.12502. [PubMed: 24848816].

45. Zapardiel I, Delafuente-Valero J, Bajo-Arenas JM. Renal angiomyolipoma during pregnancy: review of the literature. Gynecol Obstet Invest. 2011;72(4):217-9. doi: 10.1159/000329328. [PubMed: 21876331].

46. Konosu-Fukaya S, Nakamura Y, Fujishima F, Kasajima A, McNamara KM, Takahashi Y, et al. Renal epithelioid angiomyolipoma with malignant features: Histological evaluation and novel immunohistochemical findings. Pathol Int. 2014;64(3):133-41. doi: 10.1111/pin.12142. [PubMed: 24698423].

47. Bissler JJ, McCormack FX, Young LR, Elwing JM, Chuck G, Leonard JM, et al. Sirolimus for angiomyolipoma in tuberous sclerosis complex or lymphangioleiomyomatosis. N Engl J Med. 2008;358(2):140-51. doi: 10.1056/NEJMoa063564. [PubMed: 18184959].

48. Dabora SL, Franz DN, Ashwal S, Sagalowsky A, DiMario FJ, Miles D, et al Multicenter phase 2 trial of sirolimus for tuberous sclerosis: kidney angiomyolipomas and other tumors regress and VEGF- D levels decrease. PLoS One. 2011;6(9):e23379. doi: 10.1371/journal.pone.0023379. [PubMed: 21915260].

49. Cabrera-Lopez C, Marti T, Catala V, Torres F, Mateu S, Ballarin J, et al. Assessing the effectiveness of rapamycin on angiomyolipoma in tuberous sclerosis: a two years trial. Orphanet J Rare Dis. 2012;7:87. doi: 10.1186/1750-1172-7-87. [PubMed: 23140536].

50. Bissler JJ, Kingswood JC, Radzikowska E, Zonnenberg BA, Frost M Belousova E, et al. Everolimus for angiomyolipoma associated with tuberous sclerosis complex or sporadic lymphangioleiomyomatosis (EXIST-2): a multicentre, randomised, double-blind, placebocontrolled trial. Lancet. 2013;381(9869):817-24. doi: 10.1016/S01406736(12)61767-X. [PubMed: 23312829].

51. Kingswood JC, Jozwiak S, Belousova ED, Frost MD, Kuperman RA, Bebin EM, et al. The effect of everolimus on renal angiomyolipoma in patients with tuberous sclerosis complex being treated for subependymal giant cell astrocytoma: subgroup results from the randomized, placebo-controlled, Phase 3 trial EXIST-1. Nephrol Dial Transplant. 2014;29(6):1203-10. doi: 10.1093/ndt/gfu013. [PubMed: 24729041]. 